\title{
Cartilage-hair hypoplasia: a spectrum of clinical and radiological findings
}

\author{
Yoram Faitelson $^{\mathrm{a} *}$ and David Manson ${ }^{\mathrm{b}}$
}

\begin{abstract}
Introduction: Cartilage-hair hypoplasia $(\mathrm{CHH})$ is a rare skeletal dysplasia that presents with various degrees of immunodeficiency, short stature, and a susceptibility to malignancies. Individuals with $\mathrm{CHH}$ can present with severe combined immunodeficiency or combined immunodeficiency and are at risk for severe and unusual infections irrespective of their laboratory findings. In addition, individuals with $\mathrm{CHH}$ can present with variable skeletal abnormalities, mainly involving the metaphysis of long bones. $\mathrm{CHH}$ is a rare disease and familiarity with the variable features is crucial for diagnosis.

Methods: We report the clinical, radiological, and genetic findings for 5 patients with proven diagnoses of $\mathrm{CHH}$.

Results: In this study we describe a cohort of patients with $\mathrm{CHH}$ and present their clinical findings and progressions. In addition, we present the radiological images and the immunological investigations that were done in these patients. Although all the patients in our cohort had poor cellular immunity, they had a variable clinical course. Three out of 5 patients received a bone marrow transplant (BMT) and 2 out of 5 died at an early age (1 after BMT). Those who had poor humoral function had a worse prognosis compared with those with good humoral function. The skeletal findings were characteristic for $\mathrm{CHH}$.

Conclusion: $\mathrm{CHH}$ is a disease with a variable presentation. Clinicians should be aware of the characteristic skeletal and immunological findings to identify the disease as early as possible.

Statement of novelty: We present novel clinical and radiological findings in patients with variable RMRP gene mutations.
\end{abstract}

\section{Introduction}

Cartilage-hair hypoplasia $(\mathrm{CHH})$ is a rare skeletal dysplasia inherited as an autosomal recessive trait. It was first described among the Old Order Amish and the Finnish population (McKusick et al. 1965) and it is caused by mutations in the ribonuclease mitochondrial RNA-processing (RMRP) gene (Sulisalo et al. 1993; Ridanpää et al. 2001). The syndrome's hallmarks include various degrees of immunodeficiency, short stature, fine sparse hair, Hirschsprung disease, and a susceptibility to hematologic malignancies. The major radiographic findings in $\mathrm{CHH}$ are short metacarpals and phalanges; short, wide iliac wings; short, thick long bones; femoral bowing; and metaphyseal dysplasia (Kwan et al. 2012).

$\mathrm{CHH}$ is caused by mutations in the RMRP (RNA component of mitochondrial RNA processing endoribonuclease) gene that encodes for the untranslated RNA component of a mitochondrial RNA-processing endonuclease, a protein-RNA complex that plays a

\footnotetext{
a Division of Immunology and Allergy, The Hospital for Sick Children, The University of Toronto, Toronto, ON, Canada; ${ }^{b}$ Department of Diagnostic Imaging, The Hospital for Sick Children, The University of Toronto, Toronto, ON, Canada
}

Submitted 2 June 2015

Accepted 22 June 2015

Available online 25 June 2015

LymphoSign Journal 2:157-164 (2015)

dx.doi.org/10.14785/lpsn-2015-0009 
role processing of ribosomal RNA (rRNA), cleavage of mitochondrial RNA (mRNA), and in cell cycle control. The most prevalent mutation among the Finnish and the Amish is the $70 \mathrm{~A}>\mathrm{G}$ (Thiel et al. 2007). In North America most cases are caused by compound herterozygous mutations that commonly affect the gene's regulatory elements (Notarangelo et al. 2008).

$\mathrm{CHH}$ can be diagnosed clinically in an individual with short stature, disproportionally short limbs, and fine hair, but confirmation of the diagnosis should be done by genetic analysis of the RMRP gene. Individuals with $\mathrm{CHH}$ can present with severe combined immunodeficiency (SCID) or combined immunodeficiency (CID) and are at risk for severe and unusual infections irrespective of their laboratory findings. Other complications also include malignancy, and autoimmunity. An early diagnosis of $\mathrm{CHH}$ is crucial to prevent morbidity and mortality from these immune-related disorders.

The short stature and radiological features are frequently the first clue for the diagnosis. However, recognition of the typical skeletal findings may be delayed as most clinicians are rarely familiar with $\mathrm{CHH}$.

Therefore, we present here the clinical and radiological features of 5 patients with $R M R P$ mutations.

\section{Case 1}

Patient 1, a female with an Ashkenazi Jewish background, was born at term to healthy parents with no known consanguinity. Although her birth weight and head circumference were around the 50th percentile, she was relatively short, as her length was below the 10th percentile. Soon after birth she was described as having fine and sparse hair, short proximal limbs, prominent occiput, overlapping of the digits, and a small umbilical hernia. The tibial and humeri length were equivalent to 30 and 29 weeks gestational age, respectively. At the age of 6 months she was found to have low IgG and was referred to the immunology clinic. At that age she didn't suffer from severe or recurrent infections and she showed only mild developmental delay of her gross motor skills. A skeletal survey showed metaphyseal cupping/scalloping in the distal femora, radial and ulna, as well as metacarpal foreshortening (Figures 1 and 2).

The initial immunological workup showed a SCID phenotype of $\mathrm{T}-\mathrm{B}+\mathrm{NK}+$, absence of the $\mathrm{T}$-cell receptor excision circle (TREC), poor T-cell function, and a low T-cell number.

At the age of 8 months the patient was diagnosed with $\mathrm{CHH}$ based on a mutation analysis that showed the common mutation $70 \mathrm{~A}>\mathrm{G}$ in the $R M R P$ gene. She received a bone marrow transplant (BMT) from a matched unrelated donor at the age of 14 months after full myeloablative conditioning (Busulfan and Cyclophosphamide) and was engrafted shortly after with no complications. Other than severe scoliosis that developed in the 2nd decade of her life (Figure 3), her longterm engraftment and immune reconstitution remain excellent.

\section{Case 2}

Patient 2, a female of French-Irish and Native American origin, was born at term with no complications. Her older sibling was diagnosed with $\mathrm{CHH}$ and
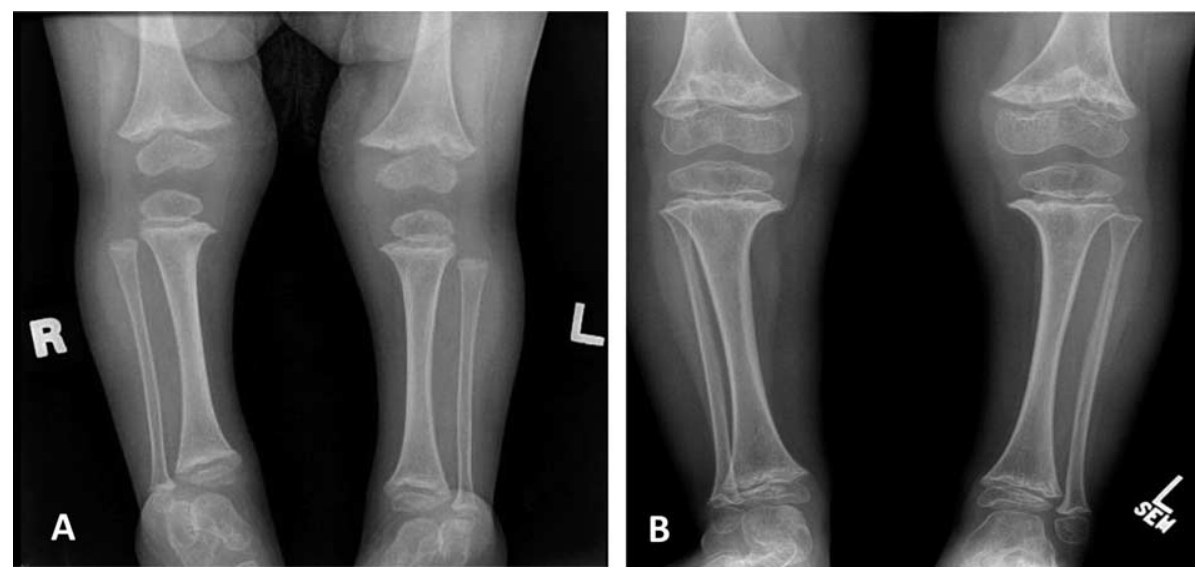

Figure 1: Lower extremity plain film of patient 1 at $2(A)$ and $4(B)$ years of age. The films demonstrate typical metaphyseal changes of cupping/scalloping and irregular "cystic" lucencies with sclerotic margins and a fragmented appearance. 


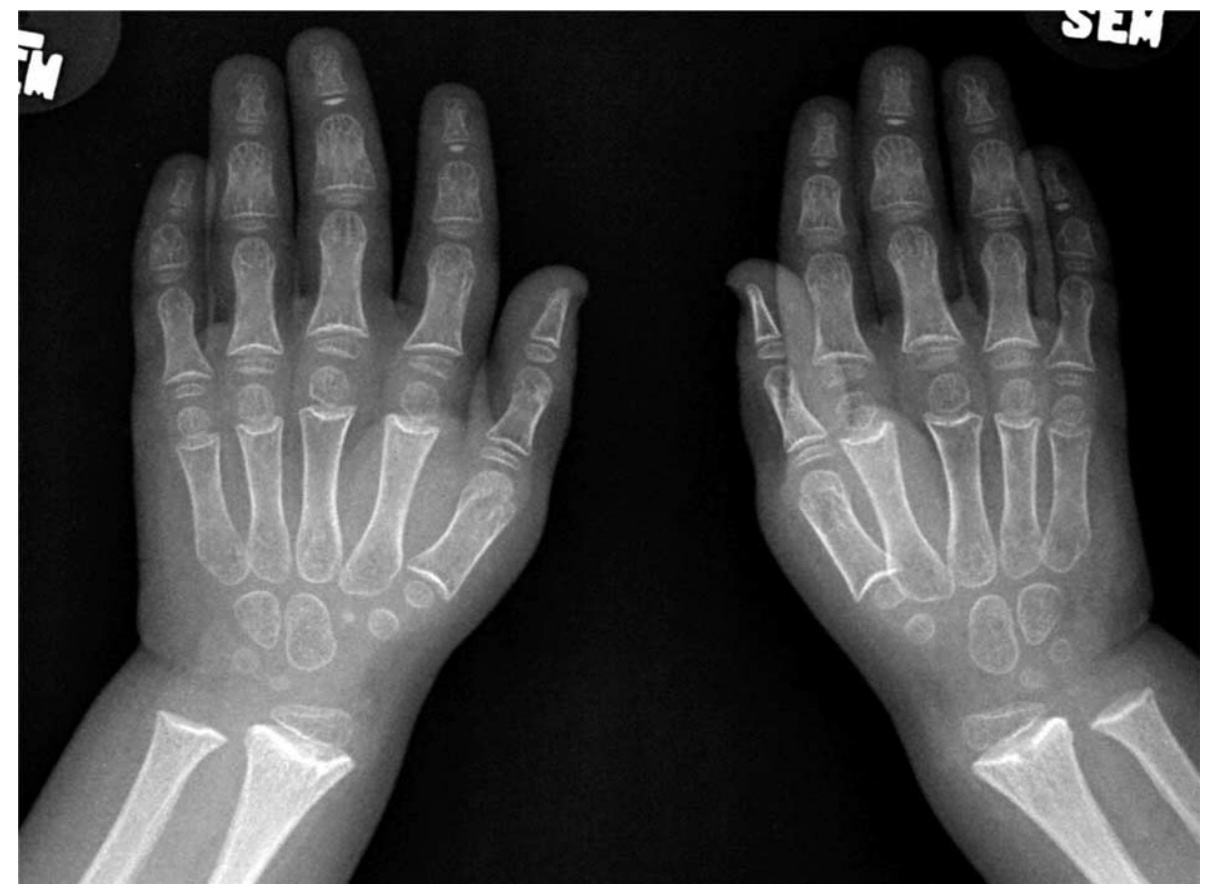

Figure 2: Hand plain film of patient 1 at 4 years of age. The film demonstrates typical metacarpal foreshortening. More subtle distal radial and ulnar metaphyseal changes are also seen.
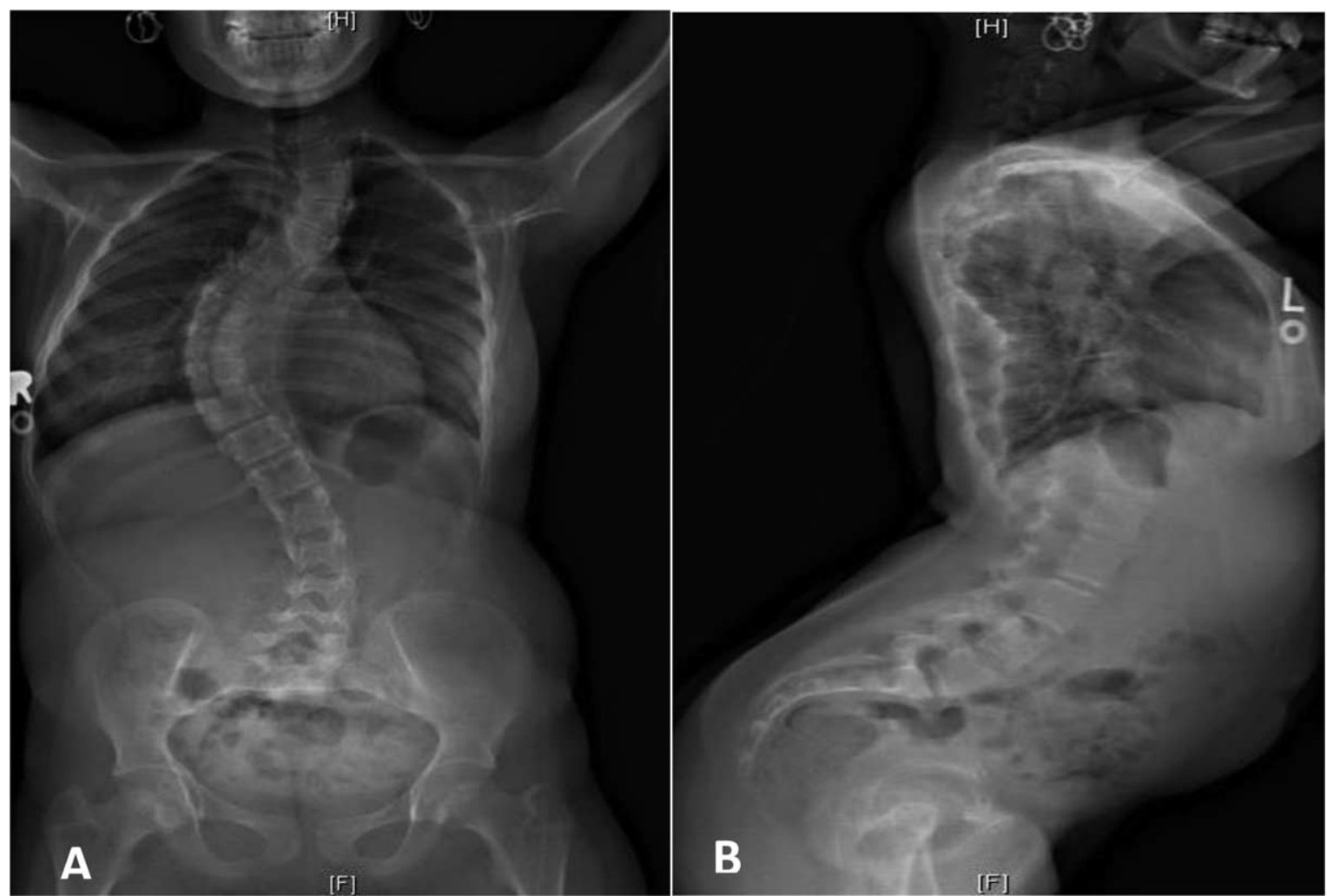

Figure 3: Plain spine posterioranterior and lateral views of patient 1 at the age of 13 years. The films demonstrate multisegmental thoracolumbar scoliosis with upper thoracic levoscoliosis measuring $56^{\circ}$, lower thoracic dextroscoliosis measuring $68^{\circ}$, and lumbar levoscoliosis at $25^{\circ}$. There is no spondylolisthesis. 


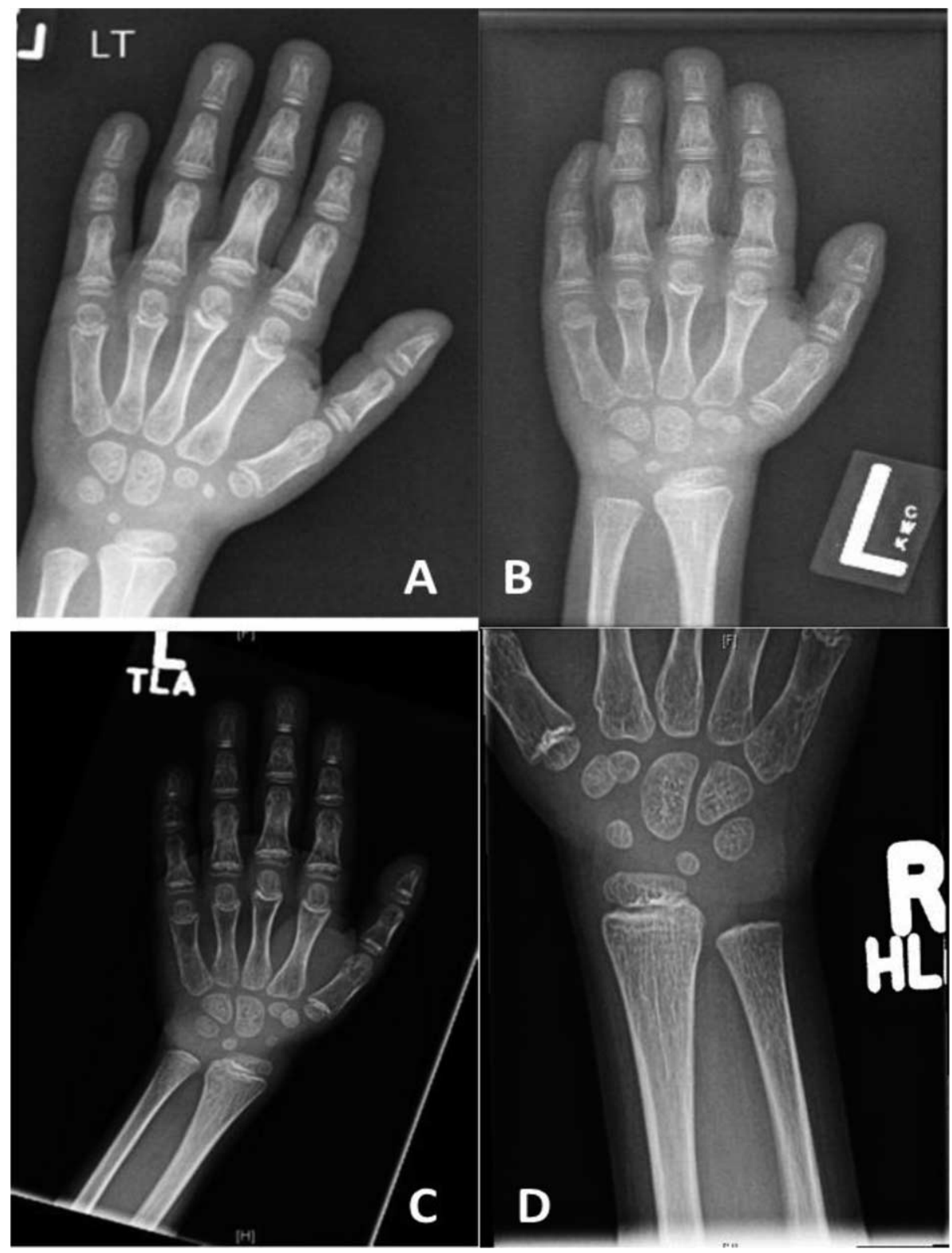

Figure 4: Upper extremity plain film of patient 3 at age $6,9,11$, and 12 years $(A, B, C$, and $D$ respectively). Views of the hands demonstrate typical metacarpal foreshortening. More subtle distal radial and ulnar metaphyseal changes are also seen.

her antenatal fetal ultrasound showed short limbs at 27 weeks of gestation. Genetic work-up demonstrated a mutation in the $R M R P$ gene $70 \mathrm{~A}>\mathrm{G}$ and she was diagnosed with $\mathrm{CHH}$ at the age of 1 month. At the age of 10 days she suffered from respiratory syncytial virus pneumonia but recovered after 2 weeks. The immune work-up in the first few months of life showed low a TREC number, T- and B-cell lymphopenia, normal levels of immunoglobulins, and poor T-cell function. She also had intermittent neutropenia that eventually resolved spontaneously. Further evaluation showed good antibody responses to vaccination with tetanus and pneumovax, although her T-cell function continued to be poor. Clinically, she suffered from constipation in the first 3 years of life but she didn't have severe or recurrent infection or signs of autoimmunity. Currently she is doing well and treated only with dapsone as a Pneumocystis jiroveci pneumonia prophylaxis.

\section{Case 3}

Patient 3, a female with an English background, was born at term to healthy parents with no known consanguinity. Family history was remarkable only for a maternal nephew with myotubular myopathy. Her birth weight was $3.9 \mathrm{~kg}$ but she failed to thrive soon after 


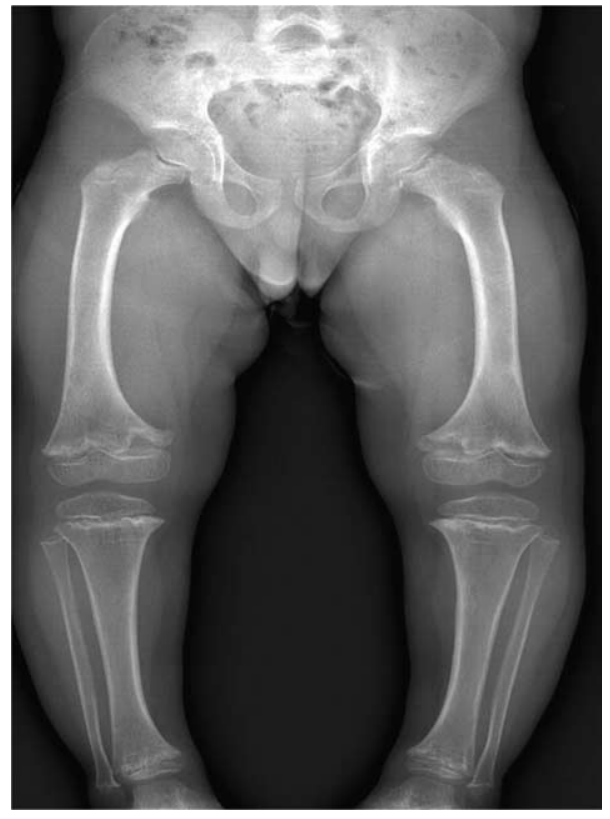

Figure 5: Lower extremity plain film of patient 4 at 7 years of age. Similar to patient 1 , there is diffuse metaphyseal flaring with irregularity adjacent to the physis in the metaphyseal regions, particularly around the knees and ankles. There is diffuse shortening of the long bones, with relative fibular elongation bilaterally.

birth. With the exception of her failure to thrive, she was doing well until the age of 2 years when she started to suffer from recurrent episodes of pneumonia, and eventually she developed bronchiectasis by the age of 6 years. She was then referred to immunology for further evaluation. Immunological workup showed a low T-cell number, poor T-cell function, and poor response to pneumococcal vaccine. She started treatment with IVIG and prophylaxis antibiotic. Skeletal films showed the characteristic skeletal changes in the metacarpals, distal ulna (Figure 4), and distal fibula.

Genetic analysis confirmed the diagnosis of $\mathrm{CHH}$ by identifying 2 mutations in the $R M R P$ gene $146 \mathrm{G}>\mathrm{A} /$ $242 \mathrm{~A}>\mathrm{G}$, each donated by the father and mother, respectively. During childhood she suffered from autoimmune hemolytic anemia. BMT was not done owing to the lack of an appropriate donor. At the age of 12 years she presented with acute enchephalitis and cognitive decline. She was treated with a broad spectrum antibiotic and anti-viral medication and eventually with immunosuppression after an infectious etiology was excluded. Unfortunately, she didn't recover and passed away a few months later.

\section{Case 4}

Patient 4, a male from French-Irish and Native American origin, was born at term with a weight of $3.4 \mathrm{~kg}$. At 30 weeks of gestation, an ultrasound revealed small long bones and a bell-shaped chest. An amniocentesis was not diagnostic but genetic investigation after birth confirmed the diagnosis of $\mathrm{CHH}$ at the age of 7 months with the finding of the common mutation $70 \mathrm{~A}>\mathrm{G}$ in the RMRP gene. Other features of $\mathrm{CHH}$ included fine sparse hair, constipation (with no evidence of Hirschsprung disease), and bowed legs (Figure 5).

His immunological investigation showed a normal level of immunoglobulins as well as adequate levels of antibodies to vaccination, but his T-cell number and function were poor on several occasions. At the age of 4 years, his bloodwork showed a restricted T-cell repertoire with clonal expansion of the VB12 and VB13 families for CD4+ cells and expansion of the VB1 family for CD8+ cells. Interestingly, the patient didn't have any severe or recurrent infections, nor did he suffer autoimmune manifestations.

Considering the patient's poor T-cell function, he had a BMT from a matched sibling donor at the age of 4.5 years. Following the transplant, at first he developed only minor acute skin graft versus host disease (GVHD), which was controlled with immunosuppression. However, a year later, he was diagnosed with chronic skin GVHD. The rash subsided with a course of steroids and methotrexate, but since then he continues to have contractures of the hands and feet. The patient continues to function well, engraftment is complete, and long-term immune reconstitution is solid.

\section{Case 5}

Patient 5, a male, was born to consanguineous parents of French Canadian origin. His birth height was below the 3 rd percentile while his weight was at the 25 th percentile. At the age of 8 weeks he developed Omenn syndrome with generalized erythroderma, lymphadenopathy, diarrhea, and irritability. His immune work-up showed low levels of immunoglobulins, clonal expansion of the $\mathrm{CD} 4+\mathrm{T}$ cell, and absent $\mathrm{CD} 8+\mathrm{T}$ cells. In addition, in vitro responses to mitogens were poor.

Genetic analysis revealed 2 mutations in the $R M R P$ gene, $154 \mathrm{G}>\mathrm{C}$ and 15 nucleotide duplication at position 
Table 1: Summary of immunological findings.

\begin{tabular}{|c|c|c|c|c|c|}
\hline $\begin{array}{l}\text { Case } \\
\text { number }\end{array}$ & Mutation & TREC & Immunophenotype & $\begin{array}{l}\text { Proliferation compared } \\
\text { with control }(\%)\end{array}$ & Immunoglobulins \\
\hline 1 & $70 A>G$ & 0 & $\mathrm{~T}-\mathrm{B}+\mathrm{NK}+$ & 16 & IgA deficiency, normal function \\
\hline 2 & $70 A>G$ & 222 & $\mathrm{~T}^{\text {low }} \mathrm{B}^{\text {low }} \mathrm{NK}+$ & 30 & Normal levels and function \\
\hline 3 & $146 \mathrm{G}>\mathrm{A} / 242 \mathrm{~A}>\mathrm{G}$ & $\mathrm{N} / \mathrm{A}$ & $\mathrm{T}^{\text {low }} \mathrm{B}-\mathrm{NK}+$ & 3 & Low levels and poor function \\
\hline 4 & $70 A>G$ & 305 & 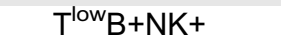 & 41 & Normal levels and function \\
\hline 5 & $\begin{array}{l}-25 \text { dupACTACTCTGTGAAGC / } \\
154 \mathrm{G}>\mathrm{C}\end{array}$ & 0 & $\mathrm{~T}^{\text {low }} \mathrm{B}^{\text {low }} \mathrm{NK}+$ & 24 & Low levels and poor function \\
\hline
\end{tabular}

Note: Proliferation was done with PHA as mitogen. (T - <500 CD3+ cells/ $\mu \mathrm{L} ; \mathrm{B}-<100$ cells $/ \mu \mathrm{L} ; \mathrm{T}^{\text {low }},<1000 \mathrm{CD} 3+$ cells $/ \mu \mathrm{L} ; \mathrm{B}^{\text {low }}<300 \mathrm{cells} / \mu \mathrm{L} ; \mathrm{N} / \mathrm{A}, \mathrm{not}$ available.)

-25 , each donated by the mother and father, respectively. At the age of 8 months he received a matched unrelated donor BMT but developed severe GVHD post-transplant. He suffered from severe skin involvement of his GVHD, acute respiratory distress syndrome with pulmonary vasculopathy, hypertension, renal failure, and secondary hypertrophic cardiomyopathy. He was treated with multiple agents against GVHD but continued to have recurrent exacerbations of GVHD and deterioration of his cardiorespiratory status. He died at the age of 3 years and 4 months from multi-organ failure.

Table 1 summarizes the immunological findings of Cases 1-5.

\section{Discussion}

$\mathrm{CHH}$ is a rare autosomal recessive skeletal dysplasia with severe short stature; characteristic skeletal changes affecting mainly the metaphysis; and extraskeletal features involving the immune, hematologic, and the gastrointestinal system. The phenotypic features correlate with the degree of reduced rRNA or mRNA cleavage. $R M R P$ mutations that reduce rRNA cleavage are associated with bone dysplasia, whereas defects that decrease mRNA cleavage are associated with hair hypoplasia, immunodeficiency, and hematologic abnormalities (Thiel et al. 2007; Notarangelo et al. 2008). The characteristic skeletal changes seen in $\mathrm{CHH}$ involve mainly the metaphysis with the findings of metaphyseal splaying, coarse irregularity, and lucent "cyst"-like lesions most prominent in the knees and ankles (Conwell et al. 2008). The epiphysis can also show some changes with rounding and a globular appearance. In addition, many other skeletal findings have been described including short metacarpals and phalanges; lumbar lordosis; short, wide iliac wings; femoral bowing; and scoliosis. Mild scoliosis was observed in one-fourth of the patients in 1 study and the incidence increased with age (Mäkitie et al. 1992). Indeed, 1 of our patients developed scoliosis in the 2 nd decade of life in accordance with previous studies (McKusick et al. 1965; Ray et al. 1975).

The skeletal findings in $\mathrm{CHH}$ are not only variable but can also be misleading as they are not always evident in infancy (Glass and Tifft 1999) and might even disappear after a short period of time (Kwan et al. 2012). The characteristic metaphyseal irregularities and cystic lesions typically do not appear until after 2 years of age. After the epiphysis closes, the metaphysis may remain flared, angulated, and eroded (Mäkitie and Kaitila 1993) or may be normal (van derBurgt et al. 1991; Makitie et al. 1995). Our patients demonstrate the variable skeletal findings with classical metaphyseal changes and metacarpal foreshortening.

Although metaphyseal changes are the most common skeletal finding in patients with $\mathrm{CHH}$, they are not restricted to this disorder as some other primary immunodeficiencies (PID) may present with multiple skeletal finding. Patients with Adenosine Deaminase Deficiency can develop different skeletal abnormalities with metaphyseal changes including prominent costochondral junctions (rachitic rosary), flaring of the anterior rib ends, pelvic dysplasia, squared off inferior scapula, or flattened vertebral bodies (platyspondyly) (Cederbaum et al. 1976). Patients with Schwachman-Diamond syndrome can present with metaphyseal chondrodysplasia in addition to bone marrow failure and pancreatic insufficiency (Mäkitie et al. 2004). Patients with Roifman immunoskeletal syndrome (spondyloenchondrodysplasia with immune dysregulation) have been described with metaphyseal and vertebral bone lesions with immune dysfunction and autoimmunity (Roifman and Melamed 2003). In addition, there are some reports of metaphyseal erosions in patients with deficiency of IL-1 receptor antagonist, a rare PID characterized 
with bone and skin abnormalities (Aksentijevich et al. 2009). It is important to mention that metaphyseal changes are not the only skeletal abnormalities seen in PID. Other skeletal changes such as spondyloepiphyseal dysplasia can be seen in Schimkes immuno-osseous dysplasia (short-trunk dwarfism as a result of spondyloepiphyseal dysplasia and immunologic abnormalities) (Hunter et al. 2010) and in Roifman syndrome (spondyloeiphyseal dysplasia, microcephaly, intrauterine growth restriction, growth retardation, and humoral immunodeficiency) (Roifman 1999).

Similar to the variability in the skeletal finding, the immune system in $\mathrm{CHH}$ can display a mild array of findings (Kavadas et al. 2008). Abnormal cellular immunity is present in the majority of $\mathrm{CHH}$ patients (van der Burgt et al. 1991; Mäkitie and Kaitila 1993), although there may be imperfect correlation between laboratory findings and susceptibility to infections (Makitie et al. 1998). In the Amish population, only $32 \%$ of the patients had severe or recurrent infections and only $8 \%$ of these children underwent BMT for CID (Rider et al. 2009). Irrespective of clinical phenotype, most patients in that study had lymphopenia and reduced lymphocyte proliferation in response to mitogens. In our small cohort, all the patients showed poor T-cell function with poor response to mitogen and a low TREC number, but only 2 patients had poor humeral function. Three out of the 5 patients had a BMT and 2 out of the 5 passed away in early age (one from GVHD post-BMT and one from encephalitis). Interestingly, the 2 patients who passed away in our cohort and the patients who needed BMT in the study by Rider et al. (2009) are the patients with the poor humeral function, a finding that suggests that poor humeral function is a bad prognostic factor in $\mathrm{CHH}$. One of our patients presented with Omenn syndrome (Roifman et al. 2006), which is an unusual presentation of $\mathrm{CHH}$ that proves mutations in the RMRP RNA gene might be associated with a more complex presentation than the classical one. Involvement of other systems such as the gastrointestinal system has been described in $\mathrm{CHH}$ patients (mainly Hirschprung's disease), but was not common in our cohort. Two of our patients had a history of constipation but none needed significant intervention. Malignancy was not seen in our cohort, but our patients are still young and this complication may appear later in life.

In summary, we have illustrated the skeletal changes typical of $\mathrm{CHH}$. When present they should trigger a thorough assessment of the immune system, especially when such patients suffer repeated infections.

\section{REFERENCES}

Aksentijevich, I., Masters, S.L., Ferguson, P.J., Dancey, P., Frenkel, J., van Royen-Kerkhoff, A., Laxer, R., Tedgård, U., Cowen, E.W., Pham, T.-H., Booty, M., Estes, J.D., Sandler, N.G., Plass, N., Stone, D.L., Turner, M.L., Hill, S., Butman, J.A., Schneider, R., Babyn, P., El-Shanti, H.I., Pope, E., Barron, K., Bing, X., Laurence, A., Lee, C.R., Chapelle, D., Clarke, G.I., Ohson, K., Nicholson, M., Gadina, M., Yang, B., Korman, B.D., Gregersen, P.K., Van Hagen, P.M., Hak, A.E., Huizing, M., Rahman, P., Douek, D.C., Remmers, E.F., Kastner, D.L., and Goldbach-Mansky, R. 2009. An autoinflammatory disease with deficiency of the interleukin-1-receptor antagonist. N. Engl. J. Med. 360(23):2426-2437. PMID: 19494218. doi: 10.1056/NEJMoa0807865.

Cederbaum, S.D., Kaitila, I., Rimoin, D.L., and Stiehm, E.R. 1976. The chondro-osseous dysplasia of adenosine deaminase deficiency with severe combined immunodeficiency. J. Pediatr. 89(5):737-742. PMID: 978320.

Conwell, L.S., Hermanns, P., and Zanki, A. 2008. Short stature and metaphyeal dysplasia due to cartilagehair hypoplasia. J. Pediatr. Endocrinol. Metab. 21:209-211. PMID: 18540246.

Glass, R.B.J., and Tifft, C.J. 1999. Radiologic changes in infancy in McKusick cartilage hair hypoplasia. Am. J. Med. Genet. 86(4):312-315. PMID: 10494084. doi: 10.1002/(SICI)1096-8628(19991008)86:4<312::AIDAJMG2>3.0.CO;2-8.

Hunter, K.B., Lücke, T., Spranger, J., Smithson, S.F., Alpay, H., André, J.-L., Asakura, Y., Bogdanovic, R., Bonneau, D., Cairns, R., Cransberg, K., Fründ, S., Fryssira, H., Goodman, D., Helmke, K., Hinkelmann, B., Lama, G., Lamfers, P., Loirat, C., Majore, S., Mayfield, C., Pontz, B.F., Rusu, C., Saraiva, J.M., Schmidt, B., Shoemaker, L., Sigaudy, S., Stajic, N., Taha, D., and Boerkoel, C.F. 2010. Schimke immunoosseous dysplasia: Defining skeletal features. Eur. J. Pediatr. 169 (7):801-811. PMID: 20013129. doi: 10.1007/s00431009-1115-9.

Kavadas, F.D., Giliani, S., Gu, Y., Mazzolari, E., Bates, A., Pegoiani, E., Roifman, C.M., and Notarangelo, L. D. 2008. Variability of clinical and laboratory features among patients with ribonuclease mitochondrial RNA processing endoribonuclease gene mutations. J. Allergy Clin. Immunol. 122(6):1178-1184. PMID: 18804272. doi: 10.1016/j.jaci.2008.07.036. 
Kwan, A., Manning, M.A., Zollars, L.K., and Hoyme, H. E. 2012. Marked variability in the radiographic features of cartilage-hair hypoplasia: Case report and review of the literature. Am. J. Med. Genet. A. 158A(11):2911-2916. PMID: 22987807. doi: 10.1002/ ajmg.a.35604.

Mäkitie, O., Ellis, L., Durie, P.R., Morrison, J.A., Sochett, E.B., Rommens, J.M., and Cole, W.G. 2004. Skeletal phenotype in patients with Shwachman-Diamond syndrome and mutations in SBDS. Clin. Genet. 65(2): 101-112. PMID: 14984468.

Mäkitie, O., and Kaitila, I. 1993. Cartilage-hair hypoplasia-Clinical manifestations in 108 Finnish patients. Eur. J. Pediatr. 152(3):211-217. PMID: 8444246. doi: 10.1007/BF01956147.

Mäkitie, O., Marttinen, E., and Kaitila, I. 1992. Skeletal growth in cartilage-hair hypoplasia. A radiological study of 82 patients. Pediatr. Radiol. 22(6):434-439. PMID: 1437368.

Makitie, O., Kaitila, I., and Savilahti, E. 1998. Susceptibility to infections and in vitro immune functions in cartilage-hair hypoplasia. Eur. J. Pediatr. 157(10):816-820. PMID: 9809821. doi: 10.1007/s004310050943.

Makitie, O., Sulisalo, T., de la Chapelle, A., and Kaitila, I. 1995. Cartilage-hair hypoplasia. J. Med. Genet. 32 (1):39-43. PMID: 7897625. doi: 10.1136/jmg.32.1.39.

McKusick, V.A., Eldridge, R., Hostetler, J.A., Ruangwit, U., and Egeland, J.A. 1965. Dwarfism in the Amish. II. Cartilage-hair hypoplasia. Bull. Johns Hopkins Hosp. 116:285-326. PMID: 14284412.

Notarangelo, L.D., Roifman, C.M., and Giliani, S. 2008. Cartilage-hair hypoplasia: Molecular basis and heterogeneity of the immunological phenotype. Curr. Opin. Allergy Clin. Immunol. 8(6):534-539. PMID: 18978468. doi: 10.1097/ACI.0b013e328310fe7d.

Ray, H.C., and Dorst, J.P. 1973. Cartilage-hair hypoplasia. Progr. Pediatr. Radiol. 4:270.

Ridanpää, M., van Eenennaam, H., Pelin, K., Chadwick, R., Johnson, C., Yuan, B., van Venrooij, W., Pruijn, G., Salmela, R., Rockas, S., Mäkitie, O., Kaitila, I., and De La Chapelle, A. 2001. Mutations in the RNA component of RNase MRP cause a pleiotropic human disease, cartilage-hair hypoplasia. Cell. 104(2):195-203. PMID: 11207361. doi: 10.1016/S0092-8674(01)00205-7. Rider, N.L., Morton, D.H., Puffenberger, E., Hendrickson, C.L., Robinson, D.L., and Strauss, K.A. 2009. Immunologic and clinical features of 25 Amish patients with RMRP 70 A-> G cartilage hair hypoplasia. Clin. Immunol. 131(1):119-128. PMID: 19150606. doi: 10.1016/j.clim.2008.11.001.

Roifman, C.M. 1999. Antibody deficiency, growth retardation, spondyloepiphyseal dysplasia and retinal dystrophy: A novel syndrome. Clin. Genet. 55(2): 103-109. PMID: 10189087. doi: 10.1034/j.13990004.1999.550206.x.

Roifman, C.M., and Melamed, I. 2003. A novel syndrome of combined immunodeficiency, autoimmunity and spondylometaphyseal dysplasia. Clin. Genet. 63(6):522-529. PMID: 12786759. doi: 10.1034/j.13990004.2003.00033.x.

Roifman, C.M., Gu, Y., and Cohen, A. 2006. Mutations in the RNA component of RNase mitochondrial RNA processing might cause Omenn syndrome. J. Allergy Clin. Immunol. 117(4):897-903. PMID: 16630949. doi: 10.1016/j.jaci.2006.01.003.

Sulisalo, T., Sistonen, P., Hästbacka, J., Wadelius, C., Mäkitie, O., de la Chapelle, A., and Kaitila, I. 1993. Cartilage-hair hypoplasia gene assigned to chromosome 9 by linkage analysis. Nat. Genet. 3(4):338341. PMID: 7981754. doi: 10.1038/ng0493-338.

Thiel, C.T., Mortier, G., Kaitila, I., Reis, A., and Rauch, A. 2007. Type and level of RMRP functional impairment predicts phenotype in the cartilage hair hypoplasia-anauxetic dysplasia spectrum. Am. J. Hum. Genet. 81(3):519-529. PMID: 17701897. doi: $10.1086 / 521034$.

Van der Burgt, I., Haraldsson, A., Oosterwijk, J.C., van Essen, A.J., Weemaes, C., and Hamel, B. 1991. Cartilage hair hypoplasia, metaphyseal chondrodysplasia type McKusick: Description of seven patients and review of the literature. Am. J. Med. Genet. 41(3):371-380. PMID: 1789294. doi: 10.1002/ajmg.1320410320. 